EMBRYARIDDLE
Aeronautical University

SCHOLARLY COMMONS

\section{International Journal of Aviation,} Aeronautics, and Aerospace

\title{
Integration of Military Unmanned Aerial Systems (UAS) into the US National Airspace System: The Relationship Between UAS Accidents and Safety Concerns
}

\author{
Omar J. Hamilton \\ Oklahoma State University, omar.hamilton@okstate.edu \\ Timm J. Bliss \\ Oklahoma State University, timm.bliss@okstate.edu \\ Chad Depperschmidt \\ Oklahoma State University, chad.depperschmidt@okstate.edu
}

Follow this and additional works at: https://commons.erau.edu/ijaaa

Part of the Aviation Safety and Security Commons, and the Management and Operations Commons

\section{Scholarly Commons Citation}

Hamilton, O. J., Bliss, T. J., \& Depperschmidt, C. (2017). Integration of Military Unmanned Aerial Systems (UAS) into the US National Airspace System: The Relationship Between UAS Accidents and Safety Concerns. International Journal of Aviation, Aeronautics, and Aerospace, 4(1). https://doi.org/10.15394/ ijaaa.2017.1150

This Article is brought to you for free and open access by the Journals at Scholarly Commons. It has been accepted for inclusion in International Journal of Aviation, Aeronautics, and Aerospace by an authorized administrator of Scholarly Commons. For more information, please contact commons@erau.edu. 
By passing the Modernization and Reform Act of 2012, Congress created potential safety hazards by proposing the introduction of aircraft into an already congested national airspace (NAS) (FAA, 2014). The FAA has established saturation of the NAS in congested areas and recognizes the limitation of growth unless major changes are made to the NAS (FAA, 2011). The introduction of UAS into the public aviation system is a new venture that may have negative effects on the operational safety of the NAS, as well as a negative public perception. Unknowns pertaining to effects on safety include midair collision avoidance, terrain avoidance and lost link incidents. The US Government Accountability Office (GAO) has identified many of the safety concerns defined in the Modernization and Reform Act of 2012. However, some key issues remained incomplete (US GAO, 2014).

Several studies based on UAS features and the ability for the aircraft to meet safety standards were recently conducted. One such study, by CuernoRejado, C., \& Martínez-Val, R. (2011), addressed UAS civil airworthiness and the regulatory efforts from manufacturers' standpoint and how they compare to the operational procedures. Another conducted by Casarosa, C., Galatolo, R., Mengali, G., \& Quarta, A. (2004), before the new legislation passed, suggested that, "The lack of airworthiness and certification criteria for the employment of UAS vehicles in the civilian field has caused an uncontrolled proliferation of projects and the construction of a number of UAS prototypes which differ in dimension, weight, flight characteristics and payload carriage (Casarosa, 2004)." Even though these studies address safety, there has not been research conducted on the safety concerns with comparison to the accident record.

\section{Purpose of the Study}

The purpose of this study was to investigate the most common unmanned aerial system (UAS) accidents from 2009-2014 and determine if a relationship between actual UAS accidents and safety concerns regarding their integration into the National Airspace System (NAS) existed. The research survey and interview questions created by the researchers explored the most common safety concerns and why they were a specific concern of US Air Force (USAF) UAS pilots and sensor operators.

\section{Research Objective and Questions}

The research methodology was designed with the intent of producing qualitative and quantitative results to answer the following research objective and related research questions. Research Objective: Based on the most common UAS 
accidents causes and US Air Force UAS instructor and evaluator pilots and sensor operators opinions, is there a relationship between safety concerns and safety issues?

Research Questions:

1. What safety features could prevent midair collisions?

2. What safety features may prevent accidents during lost link events?

3. How many lost link incidents have occurred ending with accidents?

4. How many lost link incidents have occurred ending without accidents?

5. What are the most common UAS accidents within the last five years?

6. Have UAS meeting airworthiness requirements been involved in more accidents than UAS not meeting airworthiness requirements?

7. How do current and proposed safety features integrated into a UAS prevent the most common accident occurrences?

8. Does UAS pilot training reduce the number of UAS accidents?

\section{Research Approach}

The quantitative approach was conducted to find the most common causes of UAS incidents, accidents and mishaps between June 2009 and June 2014 through the use of online databases. To receive expert opinions on safety, the qualitative research method consisted of a research survey (Appendix A) and interview questions (Appendix B) created for US Air Force UAS instructors and evaluator pilots and sensor operators. The information gathered from the qualitative approach was compared to the quantitative findings to determine whether a relationship between the safety concerns and safety records existed.

\section{Methodology}

\section{Quantitative Data Collection and Analysis}

This study referenced US Air Force (USAF), Navy (USN) and Army (USA) accident databases to complete the quantitative data collection on UAS accidents in the last five years and to determine the most common causes for accidents. The information was solicited via Freedom of Information Act formal requests to the Navy and Army Safety Institutions. The Air Force data was compiled from the USAF Judge Advocate General public webpage. The information collected from all services was not always complete due to the nature of the operations in which the UAS was used. The USN and USA did not provide specific dates or years, but did conform to the five-year period in the study, while the USAF did provide that information. The data was compiled using a manual 
tracking method to conclude if there were specific factors for the preponderance of accidents, and to show any significant difference in the accidents based on operator factors or equipment factors.

The data collected for the quantitative study was analyzed manually. Since the data was tracked manually, each accident was placed into accident class categories that included: USAF- Class A \& Unknown; USN-Class A, B, C, H and USA-Class A, B, C, D, E. Within the class categories, the accidents were categorized by causal category: pilot error $(\mathrm{PE})$, engine failure $(\mathrm{E})$, loss of controls (CT), lost link (LL) and other (O). Additionally, causal categories were categorized by period of flight: takeoff (TO), cruise (CR), landing (L) and other $(\mathrm{O})$. From the selected categories, the totals were added to find the most common causal for the accident and most common period of flight. Lastly, categories of impacts with structures, near midair and midair collisions were recorded by the researchers.

\section{Qualitative Data Collection and Analysis}

Seven US Air Force instructor and evaluator UAS pilots and sensor operators were recruited to support the qualitative data collection. Due to Air Force regulations, the pilots and sensor operators could not provide support during duty hours or from government computers so the researchers used private emails and phone numbers to forward the research survey and conduct the interview. The seven pilots and sensor operators who completed the survey were also asked to participate in the interview element of this study. Three participants participated in the interview process. To provide a scalable measure of concerns, a Likert-type scale was used for the survey. The interviews were conducted to provide supporting data that could not be measured by the research survey.

The qualitative data was collected in two manners: (1) Likert-type scale and (2) personal interviews of each pilot and sensor operator. The qualitative Likert-type scale and participant answers were created and compiled by use of an online survey service, Survey Monkey. The online survey database provided the capability to analyze data trends of answers. The database was able to provide support to find the mean, mode and median for each completed survey. The interviews were recorded and transcribed for coding using SPSS Statistics, a software package used for statistical analysis. Approval was granted from the Institutional Review Board (IRB) at Oklahoma State University prior to conducting the study. 


\section{Instrument Validity and Reliability}

The validation of a survey instrument allows the researchers to draw meaningful and justifiable inferences from participant data (Creswell, 2004). Regarding the reliability of the instrument, Creswell (2004) states that individual scores from an instrument should be reasonably constant or stable across repeated presentations of the instrument. The two research instruments used in this study (i.e. safety concern questionnaire and the interview questions) were validated by testing with a small group of military pilots and sensor operators associated with unmanned aerial systems. Furthermore, a small group of aviation academicians reviewed and provided revisions to both instruments. For both instruments, this resulted in the elimination and replacement of several questions, as well as the rewording of other questions for clarity.

\section{Findings}

Between 2009 and 2014, there were 417 reported accidents by the US Air Force (USAF), US Navy (USN) and US Army (USA) involving UAS. Of those accidents, the USAF reported 45, USA reported 324 and the USN reported 48. Due to the sensitive nature of the UAS usage, not all services provided a breakdown of accidents by year, but provided the number of accidents and causes between the time-period requested 2009-2014. The USAF did break down accidents by years; these included 11 accidents in 2009, 7 accidents in 2010, 14 accidents in 2011, 10 accidents in 2012, and 3 accidents in 2013; 2014 numbers were not available at the time of this study. Each military service accident database was categorized into classes relevant to the specific service definition of accident class; Table 1 differentiates the numbers of accidents by class and service that were included in this study.

\section{Accident Classes}

A total of 417 total UAS accidents reported in five distinct classes from 2009-2014 between these three US military services. Of the 417 UAS accidents included in the study, the data show a disparity between accident numbers and classes between the three services. For example, the USAF and USA both had 38 and 35 Class A accidents during this time period, while the USN reported 8, but had 20 Class $\mathrm{H}$ accidents; the USAF and USA did not provide Class $\mathrm{H}$ information. To help explain this disparity, the definitions of each class are defined below to show similarities and differences of accident types. These accident classes are defined by Air Force AFI91-204 (2014), Army Regulation 385-10 (2013), Operational Navy Instruction (OPNAV) 3750.6S (2014), 
Department of Defense (DOD) (2011) and Naval Aviation Safety Management System (OPNAVINST) 3750.6S (2014).

Table 1

Accident Class Totals

\begin{tabular}{|l|l|l|l|}
\hline & $\underline{\text { Air Force }}$ & $\underline{\text { Navy }}$ & $\underline{\text { Army }}$ \\
\hline Class Totals & $\mathbf{4 5}$ & $\mathbf{4 8}$ & $\mathbf{3 2 4}$ \\
\hline$A$ & 38 & 8 & 35 \\
\hline$B$ & 0 & 5 & 72 \\
\hline$C$ & 0 & 15 & 159 \\
\hline$D$ & 0 & N/A & 57 \\
\hline$E$ & N/A & N/A & 1 \\
\hline$H$ & N/A & 20 & N/A \\
\hline Unknown & 7 & 0 & 0 \\
\hline
\end{tabular}

Class A Accidents:

- Resulted in death

- Resulted in permanent total disability

- Resulted in damage equal to or greater than \$2 million dollars

- Resulted in a destroyed aircraft (excluding UAS groups 1, 2, or 3)

Class B Accidents:

- Resulted in permanent partial disability

- Resulted in damage equal to or greater than $\$ 500,000$ dollars

- Resulted in hospitalization for inpatient care of three or more individuals (not including observation or diagnostic care)

Class C Accidents:

- Resulted in a nonfatal injury or occupational illness that caused loss of 1 or more days from work not including the day or shift it occurred (lost-workday case)

- Resulted in damage equal to or greater than $\$ 50,000$ dollars

Class D Accidents:

- Resulted in a recordable injury or illness not otherwise classified as class A, $\mathrm{B}$, or C

- Resulted in damage equal to or greater than $\$ 20,000$ dollars 
Class E Accidents:

- An Army accident resulting in total cost of property damage equal to or greater than $\$ 5,000$ but less than $\$ 20,000$

Class H Accidents:

- Hazard is delineated as an " $\mathrm{H}$ " in the severity code; hazards include near midair collisions

- A hazard is any real or potential condition that can cause injury, illness, or death to personnel; damage to or loss of a system, equipment or property; or damage to the environment

- The hazard/near miss did not exceed the Class D mishap minimum property damage threshold of $\$ 20,000$ and/or the Class D minimum injury threshold of first aid, loss of consciousness, light duty, limited duty

The disparity between classes was noted due to the dollar amount for the UAS used by each service. The USAF reported UAS accidents involving the MQ1B, MQ9, EQ4 and QRF-4C aircraft. For example, each UAS is valued over the $\$ 2,000,000$ amount listed in the Class A definition (AFI91-204), thus 38 accidents involving UAS for the USAF during the time period researched were Class A and the seven not listed as Class A were unknown due to the lack of information on cost for repair of the UAS.

The USN reported accidents involving BQM74, K-MAX, MQ-001L, MQ008B, MQ-9, RQ-1，RQ-2B，RQ-4A，RQ-7B，RQ-21B，RQ-23 and SCAN EAGLE. The UAS operated by the USN and involved in this study. The USA reported accidents involving MAV, MQ-1B, MQ-1C, MQ-5B, RQ-11, RQ-11B, RQ-7, RQ-20A and RQ-12A (WASP3). Figure 1 provides the reported UAS accidents by class from 2009-2014 timeframe.

Within each class each accident was further categorized by accident cause and period of flight. The accident cause categories included: pilot error (PE), engine (E), loss of control (CT), lost link (LL) and other (O). The period of flight categories included: takeoff $(\mathrm{T} / \mathrm{O})$, cruise $(\mathrm{CR})$, landing $(\mathrm{L})$ and other $(\mathrm{O})$.

\section{Quantitative Findings}

Safety concerns and safety issues relationship. From 2009 to 2014, the three military branches observed in this research study reported accidents caused by pilot error (PE), engine failure (E), loss of control (CT), lost link (LL) and other $(\mathrm{O})$. Figure 2 provides the most common accident causes by service, while Figure 3 provides the total number of accidents by cause over a five-year period. 


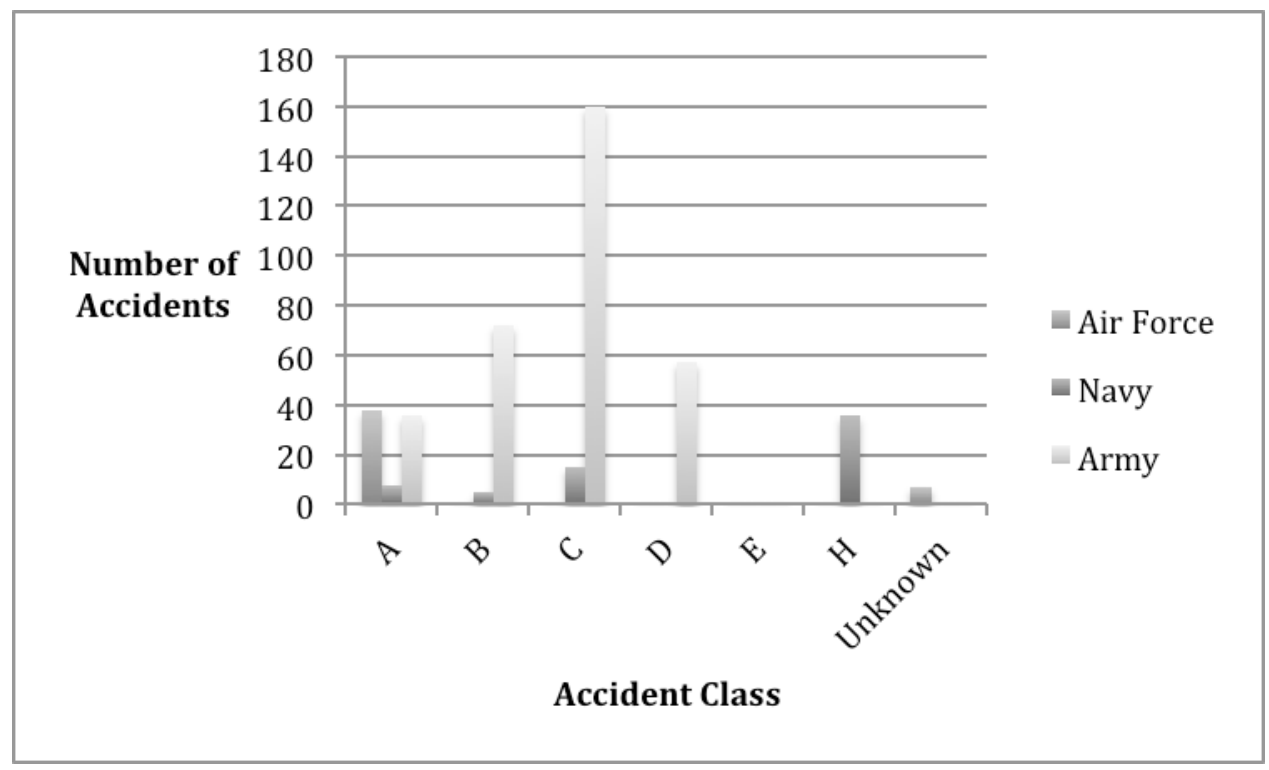

Figure 1. Accident by Class

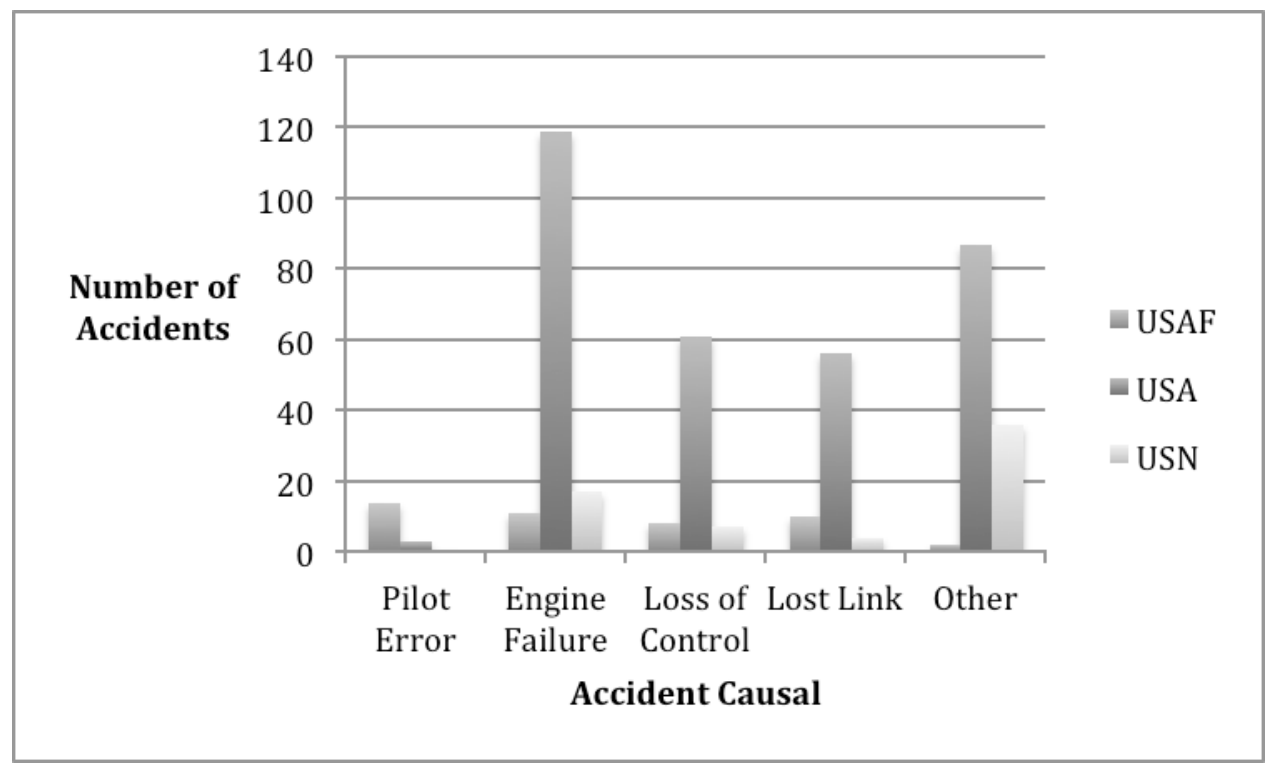

Figure 2. Most Common Accident Causes by Service 


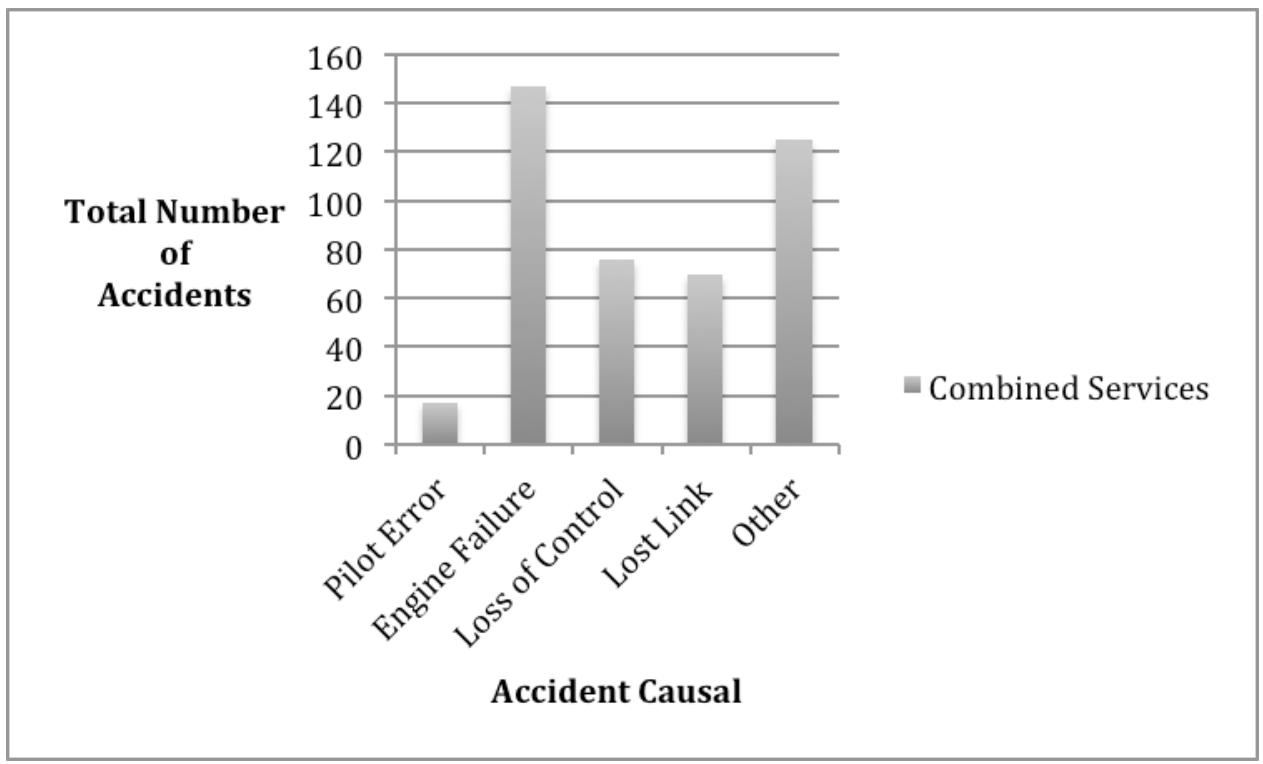

Figure 3. Most Common Accident Causes Totals

Safety concern. Seven UAS pilots and sensor operators from the USAF completed the research survey. The survey consisted of 30 Likert-scale statements relating to flight experience, flight safety concerns during phases of flight and safety concerns with regards to UAS sharing the airspace with commercial airliners.

After collecting the data from the accident databases, this data and the responses to the Likert-type scale were compared using observations of the data. An analysis of the data, employing data comparison methodologies, was conducted to determine whether any relationships between safety concerns and safety accidents existed. Comparison between the most common accidents during the three phases of flight and the level of safety concerns that each research subject had for accidents to occur during those phases of flight was completed. UAS flight profiles were categorized into takeoff, cruise and landing and the most common accidents divided into the respective phase of flight.

\section{Research questions}

What safety features could prevent midair collisions? While conducting this study, the researchers identified 15 near mid-air collisions and two mid-air collisions from 2009-2014 reported by the USN and the USA. The USN reported 15 near mid-air and zero mid-air collisions; and there were no fatalities or injuries in any of the cases reported, while the USA reported two mid- 
air collisions. Near mid-air collisions are defined by the FAA (2016) as, "an incident associated with the operation of an aircraft in which a possibility of a collision occurs as a result of proximity of less than 500 feet to another aircraft, or a report is received from a pilot or flight crew member stating that a collision hazard existed between two or more aircraft." The English Dictionary (2016) defines mid-air collision as, "an aviation accident in which two or more aircraft come into contact during flight." The USAF did not report any near mid-air or mid-air collisions. The USN near mid-air collisions consisted of nine near-mid air with other UAS, three near mid-air with fixed wing P-3 aircraft, one near-mid air with rotary wing $\mathrm{AH}-1 \mathrm{~W}$ helicopter and two near mid-air with unknown aircrafts. The USA mid-air collisions consisted of one mid-air collision between an RQ7B and fixed wing C-130 aircraft. Both aircraft sustained damage but the accident did not result in fatalities. The second mid-air collision occurred between a PUMA and an unknown (not reported) type aircraft; no fatalities were noted for this accident.

To avoid mid-air collisions, many aircraft types (including commercial airlines, military, government, and some GA aircraft) use a Terrain Collision Avoidance System (TCAS). The TCAS uses transponder information from surrounding aircraft to provide the pilots information on developing safety situations. It additionally uses Terrain Advisory Line (TAL) to provide pilots timely information to avoid pending collisions with terrain. However; currently, UAS do not have TCAS or the capability to see and avoid other aircraft. See and avoid is defined in CFR 1491.113 (b) as:

When weather conditions permit, regardless of whether an operation is conducted under instrument flight rules or visual flight rules, vigilance shall be maintained by each person operating an aircraft so as to see and avoid other aircraft. When a rule of this section gives another aircraft the right-of-way, the pilot shall give way to that aircraft and may not pass over, under, or ahead of it unless well clear. (FAA, 2015, p. 1)

According to the FAA (2013) document, Integration of Civil Unmanned Aircraft Systems (UAS) in the National Airspace System (NAS) Roadmap, "sense and avoid (SAA) capability must provide for self-separation and ultimately for collision avoidance protection between UAS and other aircraft analogous to the 'see and avoid' operations of manned aircraft that meets an acceptable level of safety," (FAA, 2013a, p. 19). Additionally, the FAA continues to state that, "unmanned flight will require new or revised operational rules to regulate the use of SAA systems as an alternate method to comply with see and avoid operational 
rules," (FAA, 2013a, p. 19). With this in mind, currently not all UAS systems have a SAA or see and avoid capability.

Technologically advanced UAS, such as the MQ-4 and other militarily used UAS, utilize cameras for the operators, but these cameras have a limited field of view. To support the SAA and see and avoid concept, UAS aircraft and UAS pilots would have to acquire and develop a "see and avoid, radar, visual sighting, separation standards, proven technologies and procedures and welldefined pilot behaviors," (FAA, 2013a, p. 19) to ensure safety of flight. To support the SAA and see and avoid policies, new technology with new piloting processes and procedures need to be developed. Currently, Ground Based Sense and Avoid (GBSAA) and Airborne Sense and Avoid (ABSAA) concepts and procedures are being studied and evaluated by public agencies and commercial companies (FAAa, 2013). These new concepts and procedures should help support future development of safety procedures for UAS.

What safety features may prevent accidents during lost link events? Not all UAS have safety features for a lost link scenario; however, all UAS identified in this research study have a built in safety feature for lost link incidents. Lost link as defined by the Federal Aviation Administration (FAA) is, "an interruption or loss of the control link" (FAA, 2013b, p. 27). The safety feature is programmed to direct the UAS to waypoints in route to its home station if it loses link to its host.

During this study, it was determined there were 71 total lost link occurrences reported from the USAF, USN, and USA. According to the FAA Roadmap (2013), "air traffic products, policies and procedures need to be reviewed and refined or developed through supporting research to permit UAS operations in the NAS," (FAA, 2013a, p. 17). These products, policies and procedures include operations and contingency procedures for UAS experiencing lost link events. The FAA has incorporated human factors into their contingency plan for dealing with lost link events, categorizing lost link events under "Predictability and contingency management," (FAA, 2013a, p. 30) research challenge. Figure 4 provides the number of lost link incidents by service and class. 


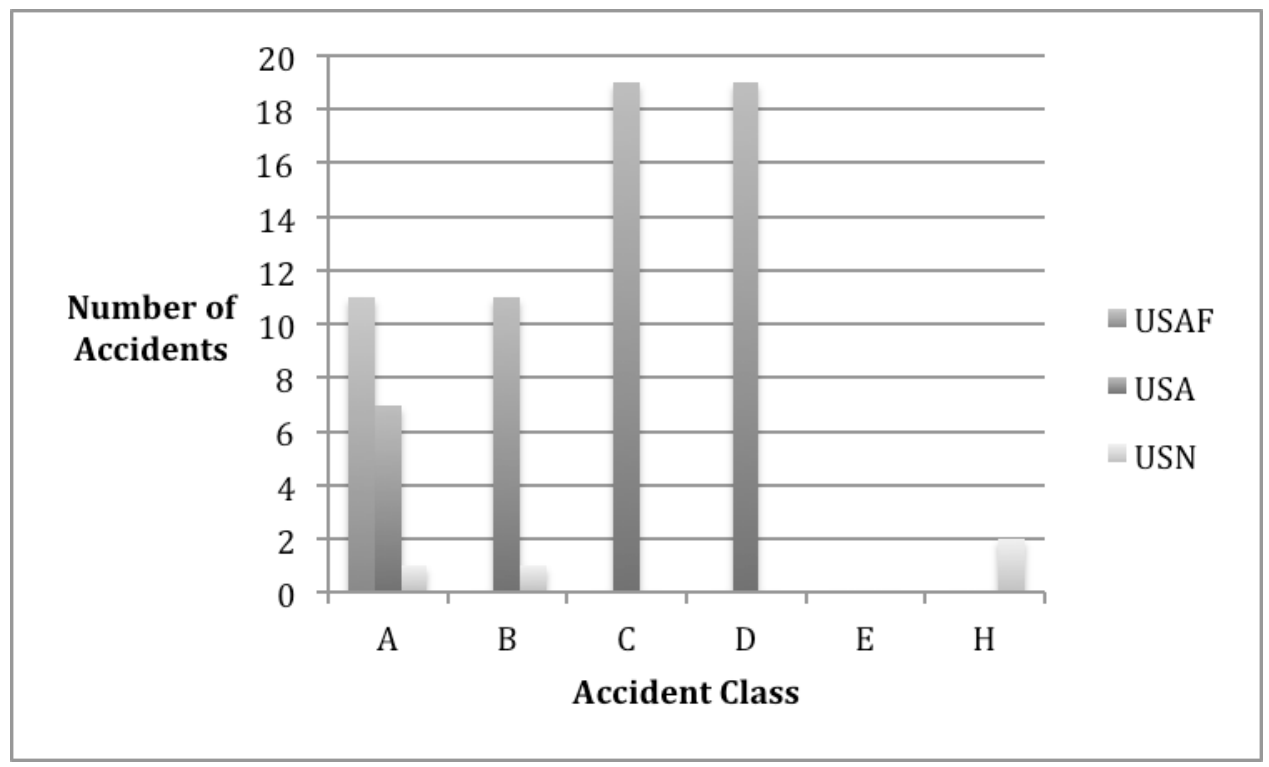

Figure 4. Lost Link

How many lost link incidents have occurred ending with accidents? As mentioned, there were 71 lost link incidents between the USAF, USA and USN, All 71 of the reported lost link incidents resulted in terrain or crash landings.

How many lost link incidents have occurred ending without accidents? All 71 lost link incidents between the USAF, USA and USN ended with flight into terrain or crash landings; therefore, none of the UAS were reported to have landed safely.

What are the most common UAS accidents within the last five years? UAS accidents identified in this study are predominantly attributable to pilot error, engine failure, loss of control, lost link and other causes (weather, electrical, runway overrun, etc.). Of these common causes, the most common accident cause was engine failure. From 2009-2014, a total of 145 engine failure incidents resulted in crashes of UAS. The Army (USA) led the incident field with 120 reported engine failures that resulted in a Class $\mathrm{A}, \mathrm{B}, \mathrm{C}$ or D accident. Most of the USA accidents resulted in a Class $C$ incident (74), which made up $47 \%$ of all Class C USA accidents reported (159). Figure 5 illustrates engine failure by military service and UAS class. 


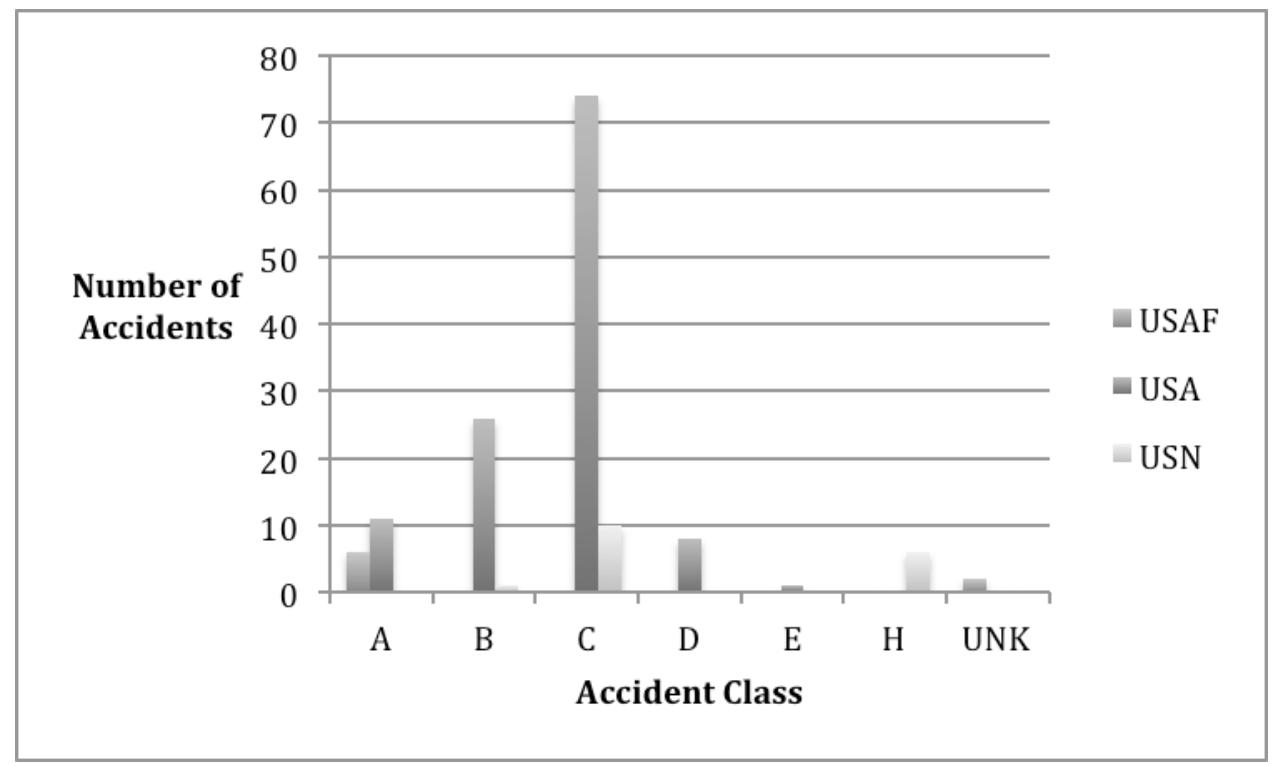

Figure 5. Engine Failure

Have UAS meeting airworthiness requirements been involved in more accidents than UAS not meeting airworthiness requirements? All UAS accident reports identified for this research study involved military use UAS. As a military UAS, they must meet strict airworthiness standards set by the Department of Defense in accordance with Department of Defense Directive 5030.61 (2013). Although military UAS may meet strict airworthiness standards, other non-military UAS or other aircraft may not hold the same level of airworthiness.

For operations of UAS within the US NAS, a UAS will receive airspace access through issuance of Certificate of Waiver or Authorization and through receipt of a special airworthiness certificate, as mentioned earlier in this research.

The FAA Roadmap (2013) states (in the future), "COAs and special airworthiness certificates will transition to more routine integration processes when a new revised operating rules and procedures are in place and UAS are capable of complying with them (FAA, 2013a, p. 5).”

In the FAA Roadmap (2013), the agency states that "to gain full access to the NAS, UAS need to be able to bridge the gap from existing systems requiring accommodations to future systems that are able to obtain a standard airworthiness certificate (p. 6)." This means that there needs to be a standard between all UAS operating in the NAS so they all meet safety standards outlined by the FAA. 
Additionally, not only will the unmanned aircraft itself meet these "airworthiness standards," but so will all subsystems and components associated with the unmanned system, i.e. control station, data link and unmanned aircraft. Ideally, with a safety standard in place and adhered to by all UAS receiving a standard airworthiness certificate, safe flight operations should increase with the number of UAS flying within the NAS.

To support meeting the certificate of waiver or authority process and to help mitigate the See And Avoid (SAA) issue that UAS will have, "some public agencies and commercial companies are seeking to develop advanced mitigations, such as Ground Based Sense and Avoid (GBSAA); test evaluations will help develop the sensor, link, and algorithm requirements that could allow GBSAA to function as a partial solution set for meeting SAA requirement (FAA, 2013a, pp. 28-29)." With the introduction of GBSAA and the continued work towards Airborne Sense and Avoid (ABSAA) concepts, the requirement for UAS to meet certification of waiver and authority requirements should make UAS flight operations safer.

How do current and proposed safety features integrated into a UAS prevent the most common accident occurrences? The RQ-1 was selected because it is currently in use by the USAF, US Navy, Customs and Border Patrol as well as other US agencies that may utilize it in the future within the NAS. The RQ-1 systems include an "inertial navigation system, satellite communications, Identification Friend or Foe (IFF) transponder, primary \& secondary control modules, electro-optical infrared sensor and synthetic aperture RADAR (SAR)," (Valdes, 2015, p. 2). These units provide some safety features for the UAS as it is more advanced than most commonly used UAS. The IFF allows for flight following, the satellite communications allow beyond-line-of-sight control of the aircraft, the optical cameras ensure the pilot can see in front of and to the side of the aircraft during day and night time operations and the SAR supports terrain mapping and "seeing through haze, clouds or smoke," (Valdes, 2015, p. 3).

Though there is an array of equipment to support the safe operations of the UAS, they do not make up for a pilot actually being inside the aircraft. The cameras that are used for the RQ-1 are limited in their side to side movement and UAS pilots have likened flying the aircraft to "flying an airplane while looking through a straw," (Valdes, 2015, p. 6). This sight limitation adds to the See and Avoid (SAA) safety issue that FAA is currently trying to overcome. In addition to the SAA challenge, the RQ-1 does not carry a Terrain Collision and Avoidance System (TCAS). Without TCAS the UAS pilot as well as other piloted aircraft within the NAS are unable to know they are on a collision heading. 
The research subjects were interviewed and asked specific questions pertaining to safety concerns regarding integration of UAS into the NAS. One of the questions posed to the research subjects was "based on your answers to the UAS safety questionnaire, describe in your professional opinion the top three greatest concerns you have with the integration of the UAS into the NAS?" Research Subject \#3 stated one of the greatest concerns was, "the lack of TCAS." An additional question posed to the research subjects was how to rectify their concerns; Research Subject \#3 stated, "Until the equipment evolves and we have onboard sense and avoid, the current processes utilized by the USAF are adequate to reduce risk."

The results of the quantitative study within this research yielded that the most common accidents occurred due to engine loss during cruise. The resulting accidents were due to loss of power and ended with partial or total destruction of the craft. In one case, a US Army UAS lost link during landing and struck a vehicle on the highway, resulting in a Class B accident. In this case, the safety features in place were not adequate to prevent an accident involving property on the ground; no one was injured during this accident.

Does UAS pilot training reduce the number of UAS accidents? The FAA Roadmap (2013) highlights the importance of training to help increase safety. The Roadmap (2013) emphasizes the importance of pilot training but also continues to require training for flight crewmembers, mechanics and air traffic controllers. The FAA recognized that for safe operations to occur for UAS flights, it does not only involve the pilot but also other crew members such as sensor operators, crew chiefs and the controllers that over watch the airways. The Roadmap (2013) details the training requirements for each of these members and explains, "UAS training standards will mirror manned aircraft training standards to the maximum extent possible," (FAA, 2013a, p. 28). According to Research Subject \#3, "the second most important issue is training; there is a misconception that less training is required to pilot an RPA. I can tell you from experience that is not the case due to the reduced situational awareness (SA) and inherent delay in the RPA operations." It is evident that training is vital to the safe operations of the UAS.

The FAA Roadmap (2013) identifies pilot training as a significant requirement for UAS integration into the NAS. The Roadmap states, "as new UAS evolve, more specific training will be developed for UAS pilots, crew members and certified flight instructors," (FAA, 2013a, p. 33). The Roadmap designated a section to iterate the goals for UAS training requirements and provide metrics to support. 
The FAA roadmap does not take into account the training that US military UAS pilots receive, and in many cases Air Force UAS pilots are previously trained manned aircraft pilots that have been selected for special duty as a UAS pilot. USAF UAS pilots are required "to complete about 140 hours of academics, must pass seven tests and run through 36 missions on T-6 simulators, for 48 hours of training (Tan, 2011)." The FAA is taking steps by including pilots, crew, maintenance, instructors, and FSDO to ensure the proper and adequate training for all involved with UAS flight within the NAS.

Research Subject \#3 describes that one of the greatest concerns for the integration of the UAS in the NAS is "lack of training for most, smaller UAS operators." Research Subject \#3 stated that "this is not the time to develop UAS 'sport pilot' equivalent certificate for any civilian operated quad-copter or smaller platform...but due to system limitations inherent to most UAS, including reduced ability to sense and avoid, solid training and procedures are required to safely integrate within the NAS." Research Subject \#2, a Senior Pilot and Evaluator Pilot for the MQ-9 as well as F-16 and EA-6B, echoes Subject \#3 with regards to training. Research Subject \#2 stated that to rectify concerns would be to "educate the aviation community as a whole about UAS operations, in particular education should focus on capabilities and limitations of the RPA and about the training the pilot receives." Research Subject \#2 continued to state, "the FAA/ATC can take many lessons on RPA incorporation with manned aircraft and operations in the NAS from the military. Specifically, they can model civilian operations after the operations from major operating airfields and airspaces in combat areas." The FAA Roadmap (2013) seems to take this into account as they have included training for more than just the pilot, crew and ATC. The Roadmap (2013) states that the UAS pilots must be trained as would a manned aircraft pilot, but this training may not be adequate enough and should go above and beyond.

As Research Subject \#2 stated the capabilities and limitations of the UAS must be educated to the aviation community; Research Subject \#3 stated that training is vital and "RPA pilots need to have a base of experience on which to relate," Subject \#3 stated that "when piloting an RPA, it's impossible to 'feel' the sensation of the aircraft oscillating (during turbulence) and the pilots must rely on experience and their instruments to diagnose this." Educating and training pilots is essential in the safe operations of the UAS in the NAS, and training policies set by the FAA should mandate these training requirements that build on experience and knowledge.

As a result of the interviews, the following nine themes emerged: 
- Tremendous growth of micro UAVs and certification process required to operate them

- Public misunderstandings of UAS capabilities

- Public capability expectations of UAS

- Overall perception that UAS cannot be safely de-conflicted from manned aircraft

- Misconception of increased airspace requirements for UAS

- Misunderstanding of naming convention of UAS in "Lost Link" event and ATC use of terms - when in a lost link event, the UAS goes into "Emergency Mission Mode" and follows way points to designated area; this does not mean the UAS is an "Emergency Aircraft."

- Lack of training for most, smaller UAS operators

- For USAF Remotely Piloted Aircraft (RPA), the lack of TCAS

- Lack of USAF RPA divert options due to launch \& recovery equipment requirements

\section{Research subject survey}

To gather the qualitative information required for this research study, a 22 Likert-type scale designed to solicit information on concern with the integration of the UAS in the NAS from the research subjects. Seven UAS pilots and Sensor Operators completed the survey. The interview portion of the qualitative study was completed with three of the pilots that completed the research survey. The seven interview questions were designed to allow the pilots to provide additional insight into their concerns with the integration of UAS into the NAS. Due to locality limitations, the interviews were conducted via email.

The 22 Likert-type scale focused on safety and concerns related to flight operations in different stages of flight, accidents involving UAS during different stages of flight, UAS accidents due to mechanical, electrical issues and concern of UAS accidents based on NAS oversaturation. The Likert-Scale statements consisted of rankings: 1 - Not at all concerned, 2 - Slightly concerned, 3 Moderately concerned, 4 - Very concerned, and 5 - Extremely concerned. The overall mean was 1.82 (level 2, slightly concerned) and Table 2 displays the mean answer for each question of the safety section of the questionnaire.

The first three statements of the survey focused on the research subjects' concern with safety of flight within the United States and saturation of the NAS. When asked if the subject believed domestic flights are unsafe, all seven answered the question with a mean concern level of 2 (Slightly concerned). When questioned about the current oversaturation of the NAS, all seven 
participants answered with a mean concern level of 2 . The next group of questions focused on safety concerns and phases of flight.

Table 2

Safety Concerns Questionnaire

\begin{tabular}{|r|r|r|l|}
\hline \multicolumn{2}{|l|}{ Safety Concern Section } \\
\hline Question \# & \multicolumn{2}{l|}{$\begin{array}{l}\text { Mean } \\
\text { Answer }\end{array}$} & \multicolumn{2}{l|}{$\begin{array}{l}\text { Question } \\
\text { Mean } \\
\text { Answer }\end{array}$} \\
\hline 1 & 2 & 12 & 1.71 \\
\hline 2 & 2.57 & 13 & 1.71 \\
\hline 3 & 2 & 14 & 2.29 \\
\hline 4 & 2 & 15 & 1.86 \\
\hline 5 & 1.86 & 16 & 1.43 \\
\hline 6 & 2.14 & 17 & 1.57 \\
\hline 7 & 1.53 & 18 & 1.43 \\
\hline 8 & 2.29 & 19 & 1.71 \\
\hline 9 & 1.43 & 20 & 1.71 \\
\hline 10 & 1.71 & 21 & 2.29 \\
\hline 11 & 1.43 & 22 & 1.86 \\
\hline
\end{tabular}

The research subjects were questioned about safety concerns with regards to aircraft accidents involving a UAS during three phases of flight (takeoff, cruise and landing); the average level of concern between the seven subjects were 1.98, or level 2 (slightly concerned). The participants were then questioned with regards to an UAS accident occurring during a lost link event, all participants responded, with a mean level of concern being 1.71. Two participants answered they were "Not at all concerned" (level 1) and the remaining five answered they were "Slightly concerned" (level 2). The next two questions pertained to UAS accidents involving midair collisions. All seven participants answered the midair collision question, resulting in a mean level of concern being 2.29. When questioned about the increase of potential accidents with terrain (homes, buildings, roads and populated areas), all seven participants responded that resulted in a mean level of concern of 1.86 .

The final section of statements posed to the seven participants focused on safety concerns with regards to an increase of congestion with UAS in the NAS. When questioned about an increase in aircraft accidents with a UAS during 
takeoff, cruise and landing, the participants averaged concern response were 1.71, 1.71 and 1.43 respectively with an overall mean of 1.61 (level 2). Again, the participants were surveyed on a lost link scenario and all answers provided a mean of 1.71, no change from an earlier statement pertaining to lost link accidents.

\section{Conclusions}

Research Objective: Based on the most common UAS accidents causes and US Air Force UAS instructor and evaluator pilots and sensor operators, is there a relationship between safety concerns and safety issues?

Between 2009 and 2014, there were 417 reported accidents by the US Air Force (USAF), US Navy (USN) and US Army (USA) involving UAS. Of those accidents, the USAF reported 45, USA reported 324 and the USN reported 48. Of the common causes, pilot error (PE), engine failure (E), loss of control (CT), lost link (LL) and other $(\mathrm{O})$, the most common accident cause was engine failure. From 2009-2014, there were at total of 145 engine failure incidents that resulted in a crash of a UAS. The Army (USA) led the field with 120 reported engine failures that resulted in a Class A, B, C or D accident. Most of the USA accidents resulted in a Class $\mathrm{C}$ incident (74), which made up $47 \%$ of all Class C USA accidents reported (159).

When interviewed, the top three concerns of the UAS pilots and sensor operators did not relate to the number of accidents or types of accidents, as the concerns involved policy and perception and not accident involvement.

The Likert-Scale findings of this study showed elevated concern of accidents during a specific phase of flight (takeoff $\&$ landing), and the amount of respondent concern of those types accidents occurring. Results also indicate a low number of incidents and accidents occurring during the cruise phase of flight and the low level of respondent concern with accidents occurring during that phase of flight. The calculated percentage of accidents during each specific phase of flight was categorized low to high: low- 0-29\%; medium- 30-50\%; high$>51 \%$.

During the takeoff phase of flight there were a total of 84 accidents of 405 accidents that occurred during one of the three phases of flight (other phase of flight not calculated) and amounted to $21 \%$ of the number of accidents. Respondent concern of accidents during this phase of flight was also low. 
During the cruise phase of flight there were a total of 218 accidents of 405 total accidents that occurred during one of the three phases of flight (other phase of flight not calculated) and amounted to 54\% of the number of accidents. Respondent level of concern of this phase of flight was low in comparison to the higher level of accidents.

During the landing phase of flight there were a total of 103 accidents of 405 accidents that occurred during one of the three phases of flight (other phase of flight not calculated) and amounted to $25 \%$ of the number of accidents. Respondent concern of the landing phase was low.

Midair and near midair accidents and level of concern were observed, with a 15 near midair collisions and 2 midair collisions being reported. Of the 405 total accidents that were recorded, $4 \%$ could have involved a near midair incident; near midair reports were not calculated in the total number of accidents observed. Less than $1 \%$ of the accidents observed involved a midair collision. Results of the three sections questioning the level of concern related to midair incidents and accidents indicated a slight respondent concern of midair collisions.

\section{Recommendations}

The FAA has crafted FAA Roadmap 2013 and implemented the UAS Integration Office to support the integration and operations of UAS. The FAA should continue to refine the Roadmap as it is integrated and update policy and regulations as required. The UAS Integration Office should provide UAS operators a way to provide feedback and lessons learned to make the process, procedures and operations of the UAS safer and efficient. Additionally, the FAA should research ways to deal with and implement contingency plans for unintentional and deliberate accidents involving UAS and further legislation must budget for the increased requirements.

The FAA Roadmap 2013 stresses the importance of training pilots, crews, maintenance and air traffic controllers on UAS operations and this should continue and evolve as the integration progresses. The training provided should be monitored and reviewed by Flight Standard District Office (FSDO) Inspectors and held to the same standards as manned aircraft and pilots. The FAA must create and uphold a standards and evaluations system that mirror manned flight operations but is also unique to UAS flight operations. FSDO Inspectors should provide inputs into the success and failures of such a system as they gather information from field inspections. 
The public perception of UAS is garnered from what is seen in media. This may skew views on operations and safety of the UAS. The public may not have a good understanding of the capabilities and limitations of the UAS as well as the background and concept of the FAA Modernization and Reform Act 2012. Research Subject \#1 and \#2 stated that their concerns included, "public misunderstandings of UAS capabilities, public capability expectations of UAS, overall perception that UAS cannot be safely de-conflicted from manned aircraft and misconception of increased airspace requirements for UAS." The UAS Integration Office should research and implement a public service campaign to inform the public of UAS operations, the concept of the Reform Act and way forward for the safe integration of the UAS into NAS. This campaign's focus should aim to inform the public of UAS operations and convey a positive perception of UAS use and safety issues. The UAS Integration Office must implement a way to track safety issues, such as accidents, near mid-air and midair collisions as well as any research done on UAS operations and provide public accessibility to this database for review. 


\section{References}

Air Force Instruction 91-204. (2014). Safety investigations and reports. Retrieved from: http://static.e-publishing.af.mil/production/ 1/af_se/publication/afi91-204/afi91-204.pdf

Army Regulation 385-10. (2013). Army safety program. Retrieved from: http://www.apd.army.mil/pdffiles/r385_10.pdf

Casarosa, C., Galatolo, R., Mengali, G., Quarta, A., (2004). Impact of safety requirements on the weight of civil Unmanned Aerial Vehicles, Aircraft Engineering and Aerospace Technology, 76(6), $600-606$.

Creswell, J. W. (2004). Educational research planning, conducting and evaluating quantitative and qualitative research (2nd ed). Columbus, $\mathrm{OH}$ : Pearson Education, Inc.

Cuerno-Rejado, C., \& Martínez-Val, R., (2011). Unmanned Aircraft Systems in the civil airworthiness regulatory frame: A case study, Journal of Aircraft, 48(4), 1351-1359.

Department of Defense Directive 5030.61. (2013). DoD airworthiness policy. Retrieved from http://www.dtic.mil/whs/directives/corres/ pdf/503061p.pdf

Department of Defense Instruction 6055.07. (2011). DoD mishap notification, investigation, reporting, and record keeping. Retrieved from http://www.dtic.mil/whs/directives/corres/pdf/605507p.pdf

English Dictionary. (2016). Definition of mid-air collision. Retrieved from http://englishdictionary.education/en/midair-collision

FAA (2011). Instrument procedures handbook. FAA-H-8261-1a. Washington, DC: Author.

FAA. (2013a). Unmanned Aircraft Systems (UAS) operational approval. Retrieved from https://www.faa.gov/documentlibrary/ media/notice/n\%208900.207.pdf 
FAA. (2013b). Integration of civil Unmanned Aircraft Systems (UAS) in the National Airspace System (NAS) Roadmap. Retrieved from http://www.faa.gov/uas/media/uas_roadmap_2013.pdf

FAA. (2014). FAA Modernization and Reform Act, reports and plans. Retrieved from https://www.faa.gov/about/plans_reports/modernization/

FAA. (2015). Code of Federal Regulations. Retrieved from http://rgl.faa.gov/Regulatory_and_Guidance_Library/rgFAR.nsf/0/934f0a 02e17e7de086256eeb005192fc!OpenDocument

FAA. (2016). FAA Aviation Safety Information Analysis and Sharing. Retrieved from http://www.asias.faa.gov/

Operational Navy Instruction 3750.6S. (2014). Naval Aviation Safety Management System. Retrieved from http://www.public. navy.mil/comnavsafecen/ documents/instructions/opnavinst _3750_6s_13may14.pdf

Tan, M. (2011). Unmanned aircraft program takes on first class. Retrieved from http://www.airforcetimes.com/news/2011/01/air-force-rpa-programgraduates-first-class-012411w/

US Government Accountability Office. (2014). Efforts made toward integration into the National Airspace continue, but many actions still required. Retrieved from http://www.gao.gov/assets/670/667346.pdf

Valdes, R. (2015). How the Predator UAV works. Retrieved from $\mathrm{http} / / /$ science.howstuffworks.com/predator.htm 
Hamilton et al.: Integration of M ilitary UAS into the US National Airspace System

Appendix A

Safety Concern Questionnaire 


\section{SAFETY:}

$\begin{array}{lllll}1 & 2 & 3 & 4 & 5 \\ \text { Not Concerned } & \text { Slightly Concerned } & \text { Moderately Concerned } & \text { Very Concerned } & \text { Extremely Concerned }\end{array}$

On a scale of 1 - 5 with regards to standard manned flight, please rate your level of concern as it pertains to:

1. Belief that flying within the domestic United States is not safe?

$\begin{array}{lllll}1 & 2 & 3 & 4 & 5\end{array}$

2. Domestic airliner's safety record when you are flying in a commercial airliner?

$\begin{array}{lllll}1 & 2 & 3 & 4 & 5\end{array}$

3. Oversaturation of the NAS with airplane operations?

$\begin{array}{lllll}1 & 2 & 3 & 4 & 5\end{array}$

4. Mid air collisions when you fly?

$\begin{array}{lllll}1 & 2 & 3 & 4 & 5\end{array}$

5. Runway incursions when you fly?

$\begin{array}{lllll}1 & 2 & 3 & 4 & 5\end{array}$

6. Being involved in an aircraft accident during takeoff?

$\begin{array}{lllll}1 & 2 & 3 & 4 & 5\end{array}$

7. Being involved in an aircraft accident at cruise altitude?

$\begin{array}{lllll}1 & 2 & 3 & 4 & 5\end{array}$

8. Being involved in an aircraft accident during landing?

$\begin{array}{lllll}1 & 2 & 3 & 4 & 5\end{array}$

Based on an increase of UAS in the NAS, on a level of 1 - 5 how concerned are you:

9. Being involved in an aircraft accident with a UAS during takeoff?
1
23
45

10. Being involved in an aircraft accident with a UAS during cruise?

$\begin{array}{lllll}1 & 2 & 3 & 4 & 5\end{array}$


11. Being involved in an aircraft accident with a UAS during landing?
1
23
34
5

12. If you knew that a UAS had less safety equipment than commercial airliners, how concerned would you be for airspace safety?

$\begin{array}{lllll}1 & 2 & 3 & 4 & 5\end{array}$

13. Based on your understanding and knowledge of UASs, how concerned are you that an accident would occur if a UAS lost its data connection to the operator?

$\begin{array}{lllll}1 & 2 & 3 & 4 & 5\end{array}$

14. How concerned are you that UAS in the national airspace system would cause more mid air collisions?

$\begin{array}{lllll}1 & 2 & 3 & 4 & 5\end{array}$

15. How concerned are you that the UAS in the national airspace system would increase the potential of accidents with terrain (i.e. homes, buildings, roads, populated areas)? $\begin{array}{lllll}1 & 2 & 3 & 4 & 5\end{array}$

16. There will be an increase in aircraft accidents with a UAS during takeoff?

$\begin{array}{lllll}1 & 2 & 3 & 4 & 5\end{array}$

17. There will be increases in aircraft accidents with a UAS during cruise?

$\begin{array}{lllll}1 & 2 & 3 & 4 & 5\end{array}$

18. An increase in aircraft accidents with a UAS during landing?

$\begin{array}{lllll}1 & 2 & 3 & 4 & 5\end{array}$

19. Based on your knowledge of UASs safety features, how concerned would you be for airspace safety?

$\begin{array}{lllll}1 & 2 & 3 & 4 & 5\end{array}$

20. Based on your knowledge of UASs, how concerned are you that an accident would occur if a UAS lost its data connection to the operator?
$2 \quad 3 \quad 4$
5

21. How concerned are you that UAS in the national airspace system would cause more mid air collisions?

$\begin{array}{lllll}1 & 2 & 3 & 4 & 5\end{array}$


International Journal of Aviation, Aeronautics, and Aerospace, Vol. 4 [2017], Iss. 1, Art. 6

22. How concerned are you that the UAS in the national airspace system would increase the potential of accidents with terrain (i.e. homes, buildings, roads, populated areas)? $\begin{array}{lllll}1 & 2 & 3 & 4 & 5\end{array}$ 
Hamilton et al.: Integration of M ilitary UAS into the US National Airspace System

Appendix B

Interview Questions 
- Briefly describe your aviation experience to include training, flight hours, pilot or aircrew experience.

- Briefly describe your experience and knowledge of unmanned aerial systems to include any piloting or sensor operator experience or any research you've accomplished.

- Briefly describe your duties in the current position you hold to include training, years of experience and daily duties.

- Describe your experience conducting safety inspections, mishap investigations and/or accident investigations.

- Based on your answers to the unmanned aerial system (UAS) safety questionnaire, describe in your professional opinion the top three greatest concerns you have with the integration of the UAS in the National Airspace System (NAS).

- Based on your answers to your greatest concerns of the UAS integration into the NAS, what needs to be done to rectify those top three concerns?

- In your overall assessment, do you feel the integration of the UAS into the NAS is a major safety concern or do you feel that with the current direction of the integration there will be minimal impact to safety? 